\title{
A Guide to Creating Gender-Sensitive Health Services
}

Spring 2007

2nd Edition

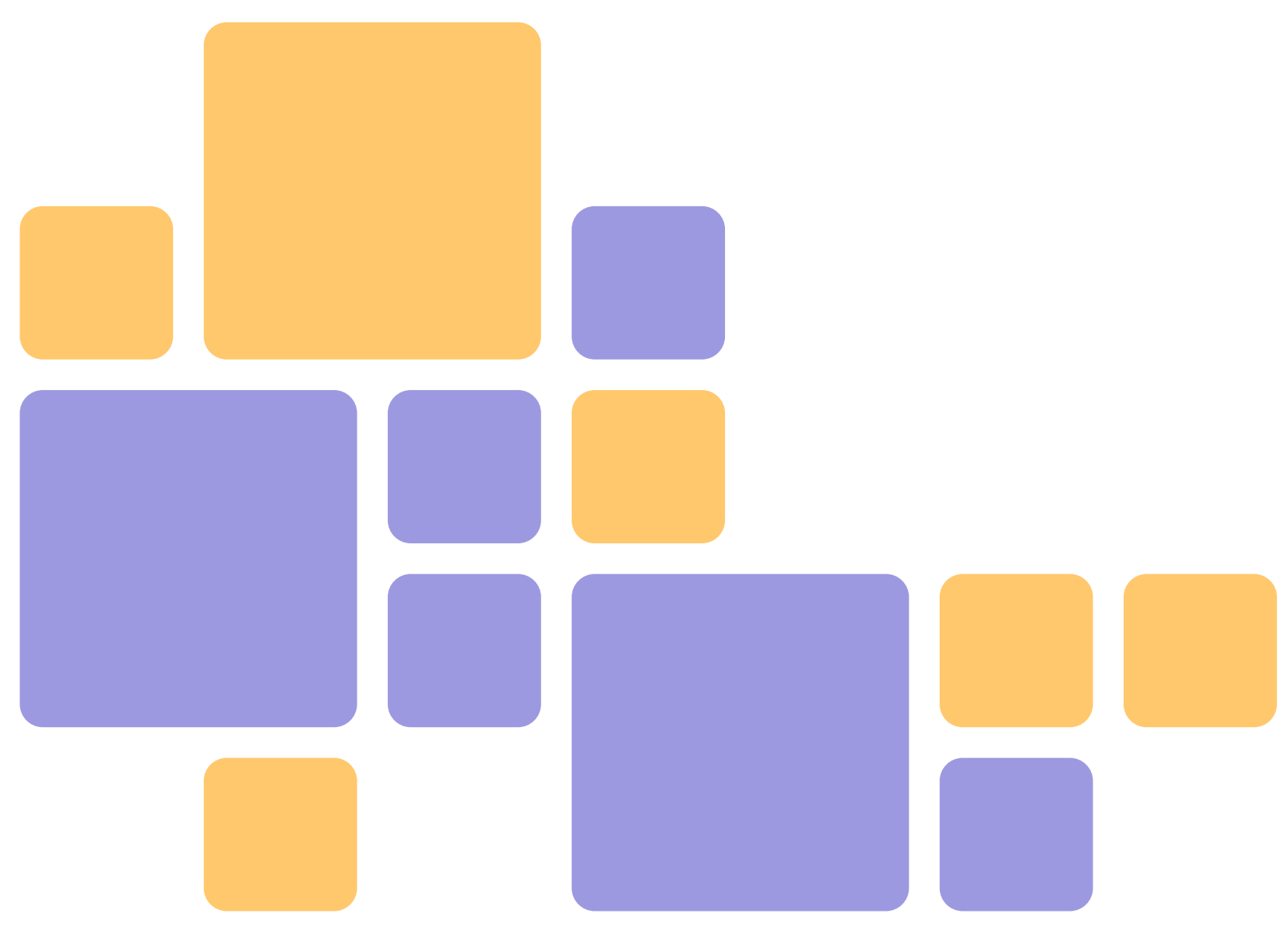




\section{The Women's Health Council}

The Women's Health Council is a statutory body established in 1997 to advise the Minister for Health and Children on all aspects of women's health. Following a recommendation in the Report of the Second Commission on the Status of Women (1993), the national Plan for Women's Health 1997-1999 was published in 1997. One of the recommendations in the Plan was that a Women's Health Council be set up as 'a centre of expertise on women's health issues, to foster research into women's health, evaluate the success of this Plan in improving women's health and advise the Minister for Health on women's issues generally.'

The mission of the Women's Health Council is to inform and influence the development of health policy to ensure the maximum health and social gain for women in Ireland. Its membership is representative of a wide range of expertise and interest in women's health.

The Women's Health Council has five functions detailed in its Statutory Instruments:

1. Advising the Minister for Health and Children on all aspects of women's health

2. Assisting the development of national and regional policies and strategies designed to increase health gain and social gain for women.

3. Developing expertise on women's health within the health services.

4. Liaising with other relevant international bodies which have similar functions as the Council.

5. Advising other Government Ministers at their request. 
The work of the Women's Health Council is guided by three principles:

- Equity based on diversity - the need to develop flexible and accessible services which respond equitably to the diverse needs and situations of women

- Quality in the provision and delivery of health services to all women throughout their lives

- Relevance to women's health needs

In carrying out its statutory functions, the Women's Health Council has adopted the WHO definition of health, a measure reiterated in the Department of Health's 'Quality and Fairness' document (2001). This definition states that:

\section{'Health is a state of complete physical, mental and social well being'}




\section{Contents}

Introduction 1

The Need for Gender-Sensitive Health Services 3

Frequently Asked Questions 4

Gender Inclusive Health Planning 7

Case Study: Mainstreaming Gender in Heart Health 9

Case Study: Mainstreaming Gender in Mental Health 12

Checklists

Questions to ask when analysing data 15

Questions to ask in program planning 16

Questions to ask when assessing the health 17 of the community

References 18

Additional Resources $\quad 21$ 


\section{Introduction}

Gender refers to those characteristics of men and women that are socially constructed, whereas sex refers to biologically determined characteristics. Gender affects most areas of human life because it pertains to the roles performed by men and women in society and the power relations between them. While biologically determined difference is universal, social differences between women and men are learned, changeable over time and vary both within and between cultures (Vlassoff \& Moreno, 2002). The World Health Organisation has pointed out that:

'Women and men play different roles in different social contexts... This affects the degree to which women and men have access to, and control over, the resources and decision-making needed to protect their health, resulting in inequitable patterns of health risk, use of health services and in health outcomes' (WHO, 2001a)

Clearly there are a number of sex specific diseases that apply to men or women but there are other influencing factors that determine our health. There are demographic variations in health status according to age, gender and social class, for instance, and these variations occur across the life of an individual. While there have been many positive changes in Irish society moving towards a more equitable distribution in roles and tasks between women and men, women are still the primary care givers and their social support is crucial to the well being of the population in general. In addition to women being the biological bearers of children, their social role in family support is extensive and can be particularly crucial in relative disadvantage or poverty where there are established links between ill health and poverty.

The importance that gender plays in health is now starting to be recognized at European level. The European Commission has included for the first time the realm of health as one of concern in terms of gender in the Roadmap for equality between women and men 2006-2010 (2006). In its Conclusions on Women's Health, the Council of the European Union also emphasised the need to take gender into consideration in all aspects of health (2006). This is particularly important due to evidence which suggests that women are currently discriminated against in terms of access to proper care in Europe (European Parliament, 2005). 
At national level, progress has also been made through the Health Service Executive's commitment to 'working in partnership with the Women's Health Council to develop approaches to gender mainstreaming for planning and delivery of all services' (HSE, 2005). Drawing on the models already in place internationally, this document aims to act as a guide to creating and implementing gender sensitive health services in Ireland. Looking to the excellent example that has been set by Australia, Canada and Sweden, extensive reference to the models of best practice in these countries has been included in this guide. Case studies on mental health and cardiovascular disease have also been included to demonstrate the gendered nature of health in an Irish context. 

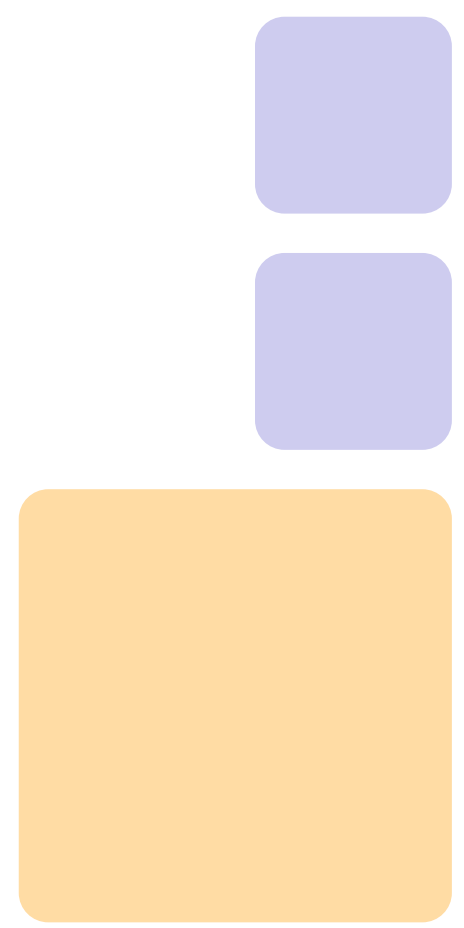

1. Gender budgeting is an application of gender mainstreaming in the budgetary processes. It means gender-based assessment of budgets, incorporating a gender perspective at all levels of the budgetary process and restructuring revenues and expenditures in order to promote gender equality (Council of Europe definition)

\section{The Need for Gender-Sensitive Health Services}

Health policies that are gender neutral assume that men and women are affected equally or in a similar manner by ill health. Because of social and biological differences, women and men face different health risks, experience difference responses from health systems, and their health-seeking behaviour and health outcomes differ (WHO, 2006). Women are more likely to be living on lower incomes, to be employed in lower paying and less stable jobs and experience greater risk of poverty than men (Callan, Layte et al., 1999).

Women tend to use the health system more frequently than men this may be due to the fact that women live longer than men, have a greater incidence of chronic illness, and have more care giving and child rearing responsibilities (Conlon, 1999).

Equity is one of the principles that underpin the national health strategy. However, equity does not necessarily mean the provision of the same treatment, but rather the provision of treatment that is fair and which will result in equality of outcomes. Hence, gender implications of health, in all their manifestations, need to be incorporated into health care provision.

In doing so, a dual strategy that incorporates gender mainstreaming as well as targeted programmes for women's health needs to be adopted (National Planning Forum for Women's Health, 2004). This type of approach allows health organisations to avoid the potential disadvantages of, on the one hand, 'ghettoising' the health needs of women, and, on the other, eliminating women-only services in the name of 'mainstreaming' (Teghtsoonian, 1999).

While it is not addressed in this document, it is also important to mention the need for gender budgeting ${ }^{1}$ in the health sector in order to achieve gender equality in health. This tool is especially crucial at times of reform, as there is substantial evidence that taxes and social insurance schemes provide the most equitable basis for health care financing (Health Evidence Network, 2005). Other schemes, such as private insurance and direct out-of-pocket payment, are likely to increase inequities, particularly in access to care and health-seeking behaviour and this may affect women more, as they generally have fewer financial resources. 

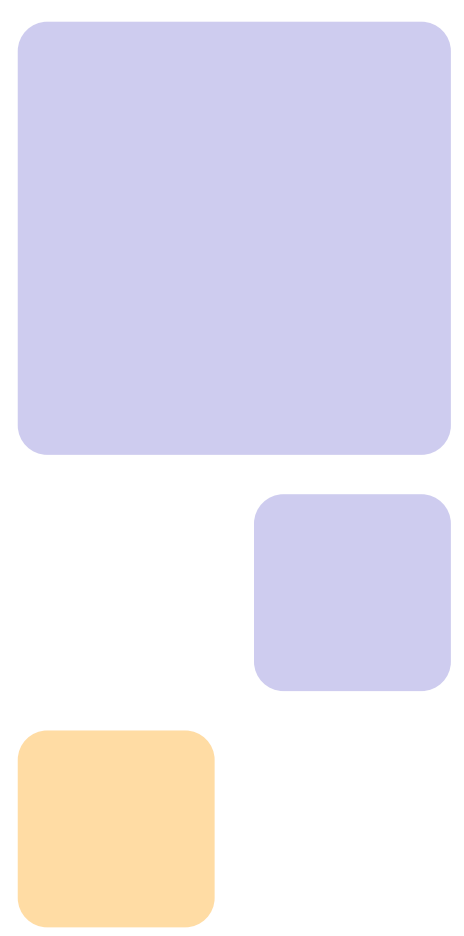

2. This section has been adapted for the Irish Context

\section{Frequently Asked Questions}

The British Colombia Ministry of Health Services and Women's Health Bureau, in their Gender Inclusive Health Planning (2001) document, set out a list of the most commonly asked questions around gender sensitive health services. The questions and answers are reproduced below:

Question: Don't women and men want the same thing from the health care system - effective, appropriate services in a timely manner?

Answer: Yes and no. Yes, both women and men value services that are effective, appropriate and delivered on time. However, "effective" and "appropriate" mean different things to women and men. We now know that women do not respond in the same way as men to many medical procedures. For example, since women's arteries are smaller, angioplasty - a procedure to clear blocked arteries - is riskier and less successful for women than men. So, it is important to remember that effective, appropriate services do not mean that women and men should receive the exact same services.

Question: What about men's health? Why are women treated like a special category of health care users?

Answer: A gender-inclusive approach to health care planning is an approach that takes into account the unique experiences and needs of both men and women - everyone has "gender", not just women. When women's health is emphasised, it is because much more is already known about men's health, not that men's health issues are less important. The vast majority of health research has been conducted by men on men and frequently the results are applied to women. This situation has sometimes led to inappropriate or ineffective interventions for women. Also, since the health care system is not immune to some of the traditional biases against women, it must become more sensitive to the unique needs of women.

\section{Question: Women live longer than men do, so they must be healthier, right?}

Answer ${ }^{2}$ : It is true that women live longer on average than men, but they experience more chronic health conditions and disabilities. In addition, women are more likely to suffer depression (WHC, 2005), 
are more likely to be prescribed psychotropic drugs (WHO, 2001), to be on waiting lists for hospital services, to rely on a medical card to cover health care costs, and in all types of residential facility, more women are present than men (NDP Gender Equality Unit, 2004). Women are also more likely than men to have a disability, autoimmune diseases, or chronic conditions such as arthritis and osteoporosis (Murphy-Lawless, 2003), and they are also more likely to be the victims of sexual assault and domestic violence (Central Statistics Office, 2004). Women access the health care system 25 per cent more often than men, even after accounting for women's unique reproductive capacity. Thus, while women do live longer than men, there is evidence that they experience a lower quality of health throughout these years.

\section{Question: What causes women and men to have different experiences of health and illness?}

Answer: As we all know from our everyday experiences, health is not only about our bodies - it is also about our mental, spiritual and emotional well-being. Consequently, where we live, our relationships, the quality of our housing, our stress levels, our workload (in and out of the home) and many other factors all impact on our health.

Factors that contribute to health are not shared equally between women and men. Women:

- earn less than men (for full-time, year-round employment);

- comprise the vast majority of lone parents;

- are more likely to experience violence in their own homes at the hands of someone they love;

- comprise the majority of unpaid caregivers for children, the sick and the elderly;

- are still underrepresented in positions of power; and,

- have more roles and responsibilities (such as paid employment, caring for children and other family members, performing household tasks and, since women comprise the majority of volunteers, volunteer tasks as well).

These different experiences lead women to have poorer health outcomes and to experience illness more often than men. 
Question: You keep talking about the "unique needs of women"what does that mean?

Answer: Obviously, women have different health care needs that relate to their unique reproductive functions (e.g., cervical screening, pregnancy, childbirth, etc.). However, even when women and men share a health concern (such as cancer), their requirements from the health care system may be very different. For example, since women live longer than men, older women are less likely to have a spouse to assist them with personal care and household chores upon leaving the hospital. Younger women are more likely to be caregivers of young children, so may be unable to rest at home. On average, women of all ages are poorer than men, so are less able to afford medications. Transportation to medical appointments and childcare arrangements are also more difficult for women due to lower incomes and multiple responsibilities. Women and men need a health care system that is sensitive to the context of their lives and that does not create barriers to access for individuals of either gender.

\section{Question: Won't a gender-inclusive health care system cost too much?}

Answer: A gender-inclusive health care system does not necessarily mean spending more money on providing more services. It does mean, however, that services provided need to be appropriate to the needs of the individual. Knowledge of how gender interacts with health, health care and the factors that contribute to health is a powerful tool for reducing the burden of illness and the resulting economic consequence to women, families and society. 


\section{Gender Inclusive Health Planning}

Gender-inclusive health planning asks whether system planners have taken into consideration the possible different needs of men and women in developing programs and policies. The British Colombia Ministry of Health Services and Women's Health Bureau list four key elements in gender-inclusive health planning:

Decision-Making Looking at decision-making structures and processes in terms of sensitivity and representation of both sexes. Keep in mind that women are under-represented in positions of influence in society; find out what women's organisations and workers with expertise in women's issues have to say about the issues. In devising programmes that target disadvantaged groups, provide opportunities for women and men from the affected and marginalised groups to take the lead in identifying and defining the issues.

Population Profile Developing a population health profile that disaggregates findings by sex wherever possible, appropriate or meaningful.

Program Inventory Conducting an inventory of existing programs and services bearing in mind the population health profile and its attendant sex and gender implications.

Program Review Designing or revising programs and services that acknowledge and address sex-related differences in health status, risk, behaviour, need and access. Involve women and men in the community in identifying and defining the issues, and make sure you consider the diversity of women and men affected.

Gender-inclusive health planning can be understood as both a process and an outcome. It is asking questions about the possible or known effects of a program, service, intervention, facility or policy for both men and women and taking an active approach to ensuring that the needs and views of women and men are taken into account in decision-making. While not all programs or policies will necessarily have different effects on men and women, it is important to ask in the planning phase whether there might be any differences, what those might be and whether those differences are relevant (British Colombia Ministry of Health Services and Women's Health Bureau, 2001). 
Good health planning is about using the available resources to help obtain the best possible health outcomes for all. However, providing the same programs and treatments for everyone in a region may not produce results which are equitable. Different programs or treatments may be necessary for women and men, boys and girls, in order to achieve the best possible results. Gender based analysis is a tool to help understand how the experiences of women and men are different, and how they are the same. In the case of health, GBA illuminates the differences in health status, health care utilisation and health needs of men and women. Gender based analysis contributes to 'evidence-based' decision-making because it broadens the scope of evidence used in the decisions, and is thus an essential tool in the allocation of resources (Donner, 2003).

The Women's Health Council has conducted a gender based analysis of two major health issues, cardiovascular disease and mental health, which have been included below. These case studies demonstrate the different issues that face men and women who experience ill-health in the two areas, and outline the gendered needs in the areas.

The Prairie Women's Health Centre of Excellence in Canada included detailed checklists for ensuring that services are gender sensitive in their Including Gender in Health Planning; A Guide for Regional Health Authorities document. These checklists have also been included in the next section. 


\section{Case Study - Mainstreaming Gender in Heart Health}

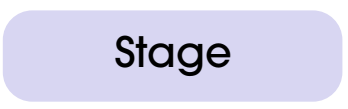

\section{Presentation}

\section{Diagnosis}

\section{Treatment}

\section{Women}

- Women develop heart disease on average 10 years later than their male counterparts (i.e. around 55 years), and the incidence of heart attack among women can lag behind men by up to 20 years

- Additionally, women have symptoms for a longer period than do men before they present for evaluation

- Women with heart disease/attack may present with symptoms such as neck, shoulder or abdominal discomfort, dyspnea, fatigue, nausea or vomiting

- Women are more likely than men to be misdiagnosed, and they are also more likely to die of their first infarction

- For women, angina is more likely to occur at rest, during sleep, or during periods of mental stress than for men

- Fewer women than men with suspected acute heart attack symptoms are referred for non-invasive tests

- Arteriography, percutaneous transluminal coronary angioplasty (PTCA), and coronary artery bypass graft surgery (CABG) are substantially lower in women than in men

- Women are less likely than men to receive any secondary preventative therapy (e.g. aspirin, beta blockers), except statins

- Women with angina are less likely to be referred to a specialist or to have revascularisation than men

- Women have higher in-hospital mortality than men after heart attack even after adjustment has been made for age

\section{Men}

- Men are younger, on average, than women when they begin to develop symptoms of heart disease (around 45 years)

- Men have been found to experience difficulty around attending the $\mathrm{GP} /$ medical services

- Symptoms of heart disease/attack in men generally consist of severe and sustained chest pain or discomfort

- Hospitalisation rates for males with ischaemic heart disease and/or acute myocardial infarction are roughly double that for females

- Slightly more men die from cardiovascular disease each year than women

- Men are more likely to die prematurely (i.e. aged less than 65 years) from cardiovascular disease than are women 


\begin{tabular}{|c|c|}
\hline Stage & Women \\
\hline $\begin{array}{c}\text { Service Delivery } \\
\text { Issues }\end{array}$ & $\begin{array}{l}\text { - Peak age range for hospitalisation of } \\
\text { females with ischaemic heart disease } \\
\text { and/or acute myocardial infarction is } \\
65 \text { to } 79 \text { years } \\
\text { - Older women may have other diseases } \\
\text { such as arthritis or osteoporosis that } \\
\text { can mask symptoms of heart disease }\end{array}$ \\
\hline $\begin{array}{l}\text { Health } \\
\text { Promotion }\end{array}$ & $\begin{array}{l}\text { - Sedentary lifestyle is the most } \\
\text { common risk factor for cardiovascular } \\
\text { disease in women. Teenage girls and } \\
\text { older women in particular should be } \\
\text { targeted for physical exercise health } \\
\text { promotion activities as they have been } \\
\text { found to have a higher prevalence of } \\
\text { being sedentary than other age groups } \\
\text { - Women may not be fully aware of their } \\
\text { range of symptoms of heart disease }\end{array}$ \\
\hline $\begin{array}{l}\text { Additional / } \\
\text { Research }\end{array}$ & $\begin{array}{l}\text { - Women have been largely ignored in } \\
\text { clinical research on cardiovascular } \\
\text { disease, as trials have largely } \\
\text { concentrated on men and on } \\
\text { manifestations of the disease among } \\
\text { men } \\
\text { - Service provision must take account of } \\
\text { the effect of family responsibilities on } \\
\text { women's access to and take-up of } \\
\text { services - e.g. rehabilitation }\end{array}$ \\
\hline
\end{tabular}

\section{Men}

- Peak age range for hospitalisation of males with ischaemic heart disease and/or acute myocardial infarction is 60 to 74 years

- $40 \%$ of men are classified as being overweight, compared to $25 \%$ of women, perhaps because men are more likely than women to frequently eat fried food. Young men, in particular, have been identified as being in need of nutrition advice and support

- Men are more likely than women to smoke and to drink to excess

- Health promotion campaigns must find new ways of communicating with men to encourage them to look after their own health more effectively 
Needs regarding cardiovascular health:

- Attention must be paid to gender equity in relation to the prevention, treatment and management of cardiovascular disease

- Measures must be put in place to increase awareness of the incidence and symptoms of cardiovascular disease among women - both for women themselves and for their health service providers

- Appropriate gender-sensitive diagnostic measures must be introduced

- Research \& clinical trials must be carried out in a gender-sensitive manner with results fully disaggregated by gender

Please refer to the Women's Health Council reports Women and Cardiovascular Disease (2003) and Integrating the Gender Perspective in Irish Health Policy: A Case Study (2005) for further details. 


\section{Case Study - Mainstreaming Gender in Mental Health}

\section{Stage}

Presentation

\section{Diagnosis}

\section{Treatment}

\section{Service Delivery}

\section{Women}

- More likely to seek help from GP

- Affected primarily by anxiety and depression

- More likely to be diagnosed with depression regardless of the symptoms

- More frequent co-morbidity of two or more problems

- More likely to be affected by eating disorders (9 in 10 cases)

- More likely to attempt suicide

- Similar rates for schizophrenia and bipolar depression but differences in symptoms, treatment and outcomes

- Twice as likely to be prescribed psychotropic drugs

- Pharmacological differences (1)

- More women discontinue medication because of weight gain

- General improvement in services needed (2)

- More women treated in private health sector - inequity to be addressed

- Women want fewer drugs and more 'talking' and complementary therapies

- Single sex areas are needed in inpatient settings

- Mother and baby units are required.

- Greater attention paid to women's many social roles in treatment, including those of partner, mother, and worker

\section{Men}

- Find it more difficult to seek help and present when often seriously ill

- Affected primarily by alcohol and drug dependence

- Less likely to be diagnosed with depression regardless of the symptoms

- Three times more likely to be diagnosed with antisocial personality disorder

- More likely to succeed in taking own life

- Similar rates for schizophrenia and bipolar depression but differences in symptoms, treatment and outcomes

- Men more likely to be referred to specialist care

- Pharmacological differences (1)

- General improvement in services needed (2)

- More likely to be heavy users of psychiatric services and experience long-term hospitalisation

- More likely to be hospitalised against their will 


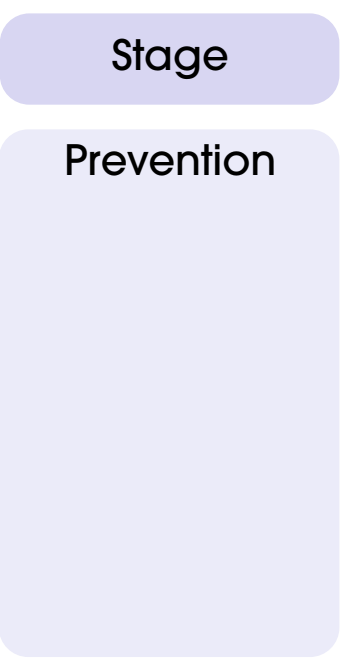

\section{Additional/ Research}

Women
- Women more likely to be subjected to
physical, emotional and sexual
violence
- Women suffer from stress caused by
multiple roles
- Women's lower status in society affects
them at personal and societal level
- Women more likely to experience
disadvantage

Men
- Men more likely to think that going to
the doctor reflects failure or personal
weakness
- More likely to use alcohol or
aggressive behaviour as more
acceptable 'male' outlets to deal with
depression (3)

- Gendered presentation of mental health problems not static but dynamic in tandem with societal changes

- Need for more gendered research. At the moment only gender disaggregated data available is HRB inpatient yearly surveys

- Need for gendered disaggregated clinical trials

\section{Comments:}

Profound psychopharmacological differences have been found between men and women. These differences have shown that the effects of drugs can be quite different in women than in men, including in the following areas:

- Getting to the liver

- Getting into the blood stream

- Excretion through kidneys

- Getting into the brain

- Action at target site in brain - effect of male/female hormones on neurotransmitter systems

- Accumulation in fat stores

- Pharmacokinetic effects of pregnancy \& lactation

Drugs have been found to stay in women's bodies for far longer than they do in men's bodies, and they also get to the brains of women and men at different rates. Women's and men's different tolerances for drugs mean that the same dosages are not appropriate for both, and women can generally be given lower doses of drugs than men. Women and men have also been found to have differences in their 
compliance and adherence to drug therapies, and the side effects of drugs can be different for women than for men.

(1) Pharmacologic treatment is more complicated in women, for a number of reasons including:

- Menstrual cycles

- Contraception

- Pregnancy

- Breastfeeding

- Drug interactions

- Impact of side effects (e.g. sedation, hypotension) on parenting

Prescribers are usually not educated as to the psychopharmacological differences between men and women as this is an area not usually covered in textbooks. In fact, women are usually prescribed more drugs than are men, leading to further concerns about the possibility of pharmacological interactions that may be harmful to women's health and well-being.

(2) A model for improved mental health services for women and men would include:

- The adoption of a person-centred approach in which the specific mental health concerns and life priorities of people are taken into account in the design and implementation of their treatment.

- The adoption of a holistic model of care, in which attention is paid to people's personal circumstances as well as their physical health.

- The expansion of community-based services, in which primary and community services are backed by inpatient psychiatric beds when necessary.

- A user-driven approach, in which current and past service users' views are sought and considered for the planning and implementation of services at every level of care provision.

- Support from advocacy services.

(3) From Getting Inside Men's Health (Richardson, 2004).

The information contained in the table can be found in The Women's Health Council's report Women's Mental Health: promoting a gendered approach to policy and service delivery (2005) 


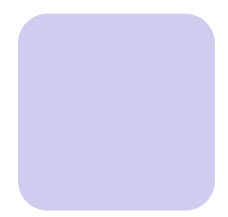

\section{Checklists}

Questions to ask when analysing data

1) Are the data separated by sex (disaggregated)?

Are they analysed by sex? If not, how can we do that?

2) Were the data collected in a way that allowed for the full participation of women and men, boys and girls?

3) Have the data been analysed considering gender both as a determinant of health and as an important influence on the other determinants of health?

4) Are women and men, boys and girls considered all together, or have differences in age and life-stage been considered? Has diversity been considered?

5) Do the data shed light on the situations of those women and men, boys and girls who carry a greater burden of illness, or whose health may be more vulnerable, including youth, seniors, those living on low incomes, people with disabilities, travellers, immigrants and refugees and those with different sexual orientations? What can the data tell us about the influence of gender on the health of women and men in these groups?

6) Are the data available only at the household/family level, when the experiences and needs of women and men, girls and boys in the family may be different?

7) How can these data be used to help us to improve the health of the women and men, boys and girls in our region? How can these data be used to help us to address gender inequities in the health of our population?

In summary, GBA has been incorporated into data analysis if:

- sex disaggregated data are presented and analysed;

- women, girls, men and boys are fully represented in the data by sex and age, as appropriate;

- data are available for individuals, not just for families;

- the effect of gender as a determinant has been considered;

- the influence of gender on other determinants has been considered;

- data about diversity among women/girls and men/boys are presented and analysed;

- data about women/girls and men/boys who carry a greater burden of illness and whose health may be more vulnerable are presented and analysed. 
Questions to ask in program planning

1) Was this program designed considering similar and different needs of women and men, boys and girls? What resources exist locally and outside our region to help to identify these needs?

2) Was the program designed considering what is already known about gender differences for this health issue?

3) Have the views of women and girls, boys and men who will be using this program been included in its design? If not, how can we gain their input?

4) Are women and men, boys and girls considered all together, or have differences in age and life-stage been considered? Has the diversity of the population been considered?

5) Has this program been designed using the available information about the situations of those women and men who carry a greater burden of illness, or whose health may be more vulnerable, including youth and seniors, those living on low incomes, people with disabilities, Traveller people, immigrants and refugees and people with different sexual orientations? What do we know, and what can we find out, about the influence of gender on the health of women and men in these groups? Where can we go for additional information?

6) Does the design of the program perpetuate existing stereotypes about women and men, boys and girls?

In summary, GBA has been incorporated into program planning if the program was designed:

- considering the similar and different needs of women, girls, men and boys;

- with input from women/girls and men/boys who will use it;

- using existing knowledge about gender differences;

- considering diversity among women/girls and boys/men;

- considering the particular needs of women/girls and boys/men who carry a greater burden of illness or whose health may be more vulnerable;

- to avoid perpetuating stereotypes about women/girls and boys/men. 
Questions to ask when assessing the health of the community

1) Does the plan to gather information include women/girls and boys/men, as appropriate?

2) How will gender affect the ways in which women and men, boys and girls participate, or do not participate, in the project? How can we change the design of the project to encourage equitable participation of both women, girls, men and boys?

3) Is this project designed so that we can collect information about the different needs and experiences of individual family members, rather than using the family as the basic unit of analysis? How do we include different types of families?

4) Has the project been designed with consideration of what is already known about gender differences for this health issue?

5) Is the project designed to gather information about the situations of those women/girls and men/boys who carry a greater burden of illness, or who may be more vulnerable? This could include youth and seniors, those living on low incomes, people with disabilities, Traveller people, immigrants and refugees and people with different sexual orientations? What do we know, and what can we find out, about the influence of gender on the health of women and men in these groups? What resources exist locally and outside of our region to help us?

6) What data about the health of our population is available, from either regional or national resources? Is it sex-disaggregated? Have I considered gender issues in analysing these data?

In summary, GBA has been incorporated into the community health assessment projects if they:

- appropriately include women/girls and men/boys as sources of information;

- encourage the equitable participation of women/girls and men/boys;

- collect information about the needs and experiences of individual family members, not just the family unit;

- gather information about those women and girls, men and boys who carry a greater burden of illness or whose health may be more vulnerable;

- use existing knowledge about gender differences;

- include gender-based analysis in the analysis of other data which are included in the project. 


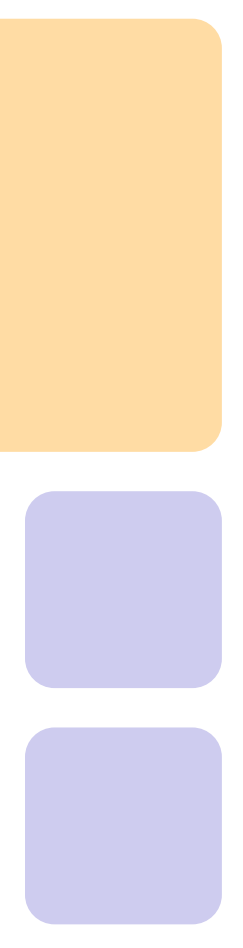

\section{References}

British Columbia Ministry of Health Services and Women's Health Bureau 2001 Gender Inclusive Health Planning.

Vancouver: British Columbia Ministry of Health Services.

http://www.healthservices.gov.bc.ca/whb/publications/gender_inclusive.pdf

Callan, T. et al (1999) Monitoring Poverty Trends: Data from the 1997

Living in Ireland Survey.

Dublin: ESRI.

Central Statistics Office 2004 Women and Men in Ireland 2004.

Dublin: The Stationery Office.

http://www.cso.ie/releasespublications/documents/other_releases/2004/

womenandmeninireland2004.pdf

Conlon, C 1999 Women - The Picture of Health?

Dublin: The Women's Health Council.

http://www.whc.ie/publications/pic-heal.pdf

Council of the European Union 2006 Council Conclusion on Women's Health.

Brussels: Council of the European Union.

Donner, L. 2003 Including Gender in Health Planning - a guide for regional health authorities.

Winnipeg: Prairies Women's Health Centre of Excellence.

http://www.pwhce.ca/pdf/gba.pdf

European Commission 2005 A Roadmap for equality between women and men 2006-2010.

Brussels: European Commission.

European Parliament 2005 Report on gender discrimination in health systems. FINAL A6-0250/2005.

Luxembourg: European Parliament.

Gender Equality Unit 2004 Women and Men in Ireland: facts and figures. Dublin: Gender Equality Unit, Department of Justice, Equality and Law Reform 
Health Evidence Network 2005 What evidence is there about the effects of health care reforms on gender equity, particularly in health? Copenhagen: WHO Regional Office for Europe.

Health Service Executive 2005 National Service Plan 2006.

Naas: Health Service Executive.

http://www.hse.ie/en/Publications/HSEPublications/FiletoUpload,2829,en.pdf

Murphy-Lawless, J. 2003 Establishing the Rationale for Gender-Specific Strategies to Improve Women's Health: The Evidence from Research. Dublin: Dept. Social Policy \& Social Work, University College Dublin.

Richardson, N. 2004 Getting Inside Men's Health.

Kilkenny: Health Promotion Department, South-Eastern Health Board.

Teghtsoonian, K. 1999 Centring Women's Diverse Interests in Health Policy and Practice: a comparative discussion of gender analysis. Halifax: Maritime Centre of Excellence for Women's Health. http://www.cewh-cesf.ca/PDF/acewh/centering-womens.dpf

Vlassoff, C. \& Moreno, C.G. 2002 "Placing gender at the centre of health programming: challenges and limitations".

Journal of Social Science and Medicine 54, pp1713-1723.

Women's Health Council 2002 Promoting Women's Health; A Population Investment for Ireland's Future.

Dublin: The Women's Health Council.

http://www.whc.ie/publications/27401WHC.pdf

Women's Health Council 2003 Women and Cardiovascular Health.

Dublin: The Women's Health Council.

http://www.whc.ie/publications/31658_WHC_Cardiovascular.pdf

Women's Health Council 2005a Integrating the Gender Perspective in Irish Health Policy: A Case Study.

Dublin: The Women's Health Council.

http://www.whc.ie/publications/WHC\%20Gender\%20Perspective\%20 report.pdf 
Women's Health Council 2005b Women's Mental Health: A Gendered Approach to Policy and Service Provision.

Dublin: The Women's Health Council.

http://www.whc.ie/publications/Women's\%20Mental\%20Health.pdf

World Health Organisation 2001a Madrid Seminar on Gender

Mainstreaming Health Policies in Europe.

http:www.euro.who.int/document/a75328.pdf

World Health Organisation 2001b Gender Disparities in Mental Health. Geneva: World Health Organisation.

World Health Organisation 2004 Gender and Women's Mental Health. Geneva: World Health Organisation.

World Health Organisation 2006 Gender, women and health: draft strategy.

Geneva: World Health Organisation.

http://www.who.int/gb/ebwha/pdf_files/EB120/b120_6-en.pdf 


\section{Additional Resources}

Ågren, G. 2003 Sweden's new public health policy.

Stockholm: Swedish Institute of Public Health.

Beck, T. 1999 Using Gender-Sensitive Indicators - a reference manual for governments and other stakeholders.

London: Commonwealth Secretariat.

Brown, S. 2001 Mainstreaming Gender in Health - from theory to practice. Victoria: Women's Health Victoria.

http://www.whv.org.au/Articles/Mainstreaming_gender.pdf

Dearn, L. 1999 Gender Sensitivity in Health Care: a background paper by Women's Health Victoria.

Melbourne: Women's Health Victoria

http://www.whv.org.au/Articles/Gender_sensitivity_health_care.pdf

Department of Health South Africa 2002 Gender Policy Guidelines for the Public Health Sector.

http://196.36.153.56/doh/docs/factsheets/guidelines/ethics-f.html

Dyson, S. 2001 Gender \& Diversity; A Workbook for an Equity Approach to Practice.

Melbourne: Women's Health in the South East.

Gender and Health Group, Liverpool School for Tropical Medicine 1998

Guidelines for the analysis of Gender and Health.

Liverpool: Liverpool School of Tropical Medicine

http://www.liv.ac.uk/lstm/hsr/gg.html

Health Canada 2000 Gender-based Analysis Policy.

Ottawa: Health Canada

http://www.hc-sc.gc.ca/english/pdf/womens/gba.pdf

K. Johnstone 2001 Criteria for Identifying Best-Practice Models in

Women's Health

Melbourne: Women's Health Victoria

http://www.whv.org.au/Articles/Best_practice.pdf 
Matlin S.A. 1998 Gender Management Systems in the Health Sector. London: Commonwealth Secretariat.

http://www.un.org/womenwatch/daw/csw/matlin.htm

SIDA 1997 A Gender Perspective in the Health Sector - handbook for mainstreaming.

Stockholm: Swedish International Development Cooperation Agency http://www.sida.se/sida/articles/9100-9199/9182/gender.pdf

Status of Women Canada 2003 Gender-based Analysis (GBA) Performance Measurement of its Application.

Ottawa: Status of Women Canada.

http://www.swc-cfc.gc.ca/pubs/gbaperformance/gbaperformance_e.pdf 
The Women's Health Council Combairle Shláinte na mBan

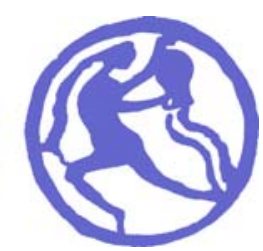

The Women's Health Council Block D, Abbey Court Irish Life Centre Abbey Street Lower

Dublin 1

Tel: +3531 8783777 Fax: +3531878 3710

E-mail: info@whc.ie Web: http://www.whc.ie 